\title{
Uma aproximação ao conceito de aura em Walter Benjamin
}

\author{
One approach to the aura's concept in Walter Benjamin
}

Anderson Fasano - Universidade de Sorocaba | Sorocaba | SP | Brasil | E-mail: anderson.fasano@prof.uniso.br (D) ORCID

José Rodrigo Paulino Fontanari - Universidade de Sorocaba | Sorocaba | SP | Brasil | E-mail: rodrigo.fontanari@prof.uniso.br

Resumo: O presente artigo busca explicitar, dentro das limitações a este tipo de gênero, o conceito aura (seus desdobramentos semânticos e suas possíveis relações com as transformações trazidas pela Modernidade) elaborado por Walter B.S. Benjamin, a fim de estabelecer um caminho para uma aproximação de sua leitura do status da Arte a partir da Fotografia e do Cinema, bem como das extensões filosófico-sociais inerentes a ela. Para tanto, o método arqueológico - enquanto resgate ou recuperação do conceito - se nos afigurou o mais pertinente ao intento aqui estabelecido como meta.

Palavras-chave: Modernidade. Fotografia. Cinema. Aura.

Abstract: The present article seeks to make explicit, within the limitations of this type of genre, the aura concept (its semantic unfolding and its possible relations with the transformations brought by Modernity) elaborated by Walter BS Benjamin, in order to establish a way for an approach to the status of Art from Photography and Cinema, as well as the philosophical-social extensions inherent in it. To do so, the archaeological method - as rescue or recovery of the concept - has appeared to us the most pertinent to the intent here set as a goal.

Keywords: Modernity. Photograph. Movie theater. Aura.

Recebido em maio de 2018. $\quad$ Aprovado em novembro de 2018. 


\section{Introdução}

Nascido em Berlim, Walter Benedix Schönflies Benjamin (1892-1940), pode ser definido como um nostálgico em tempo de crise. Vivera, assim, o drama de duas grandes guerras (1914-1918 e 1939-1945) - tendo provocado sua própria morte no começo da segunda.

Por ocasião da ascensão dos totalitarismos na Europa (o fascismo, na Itália e, mormente, o nazismo, na Alemanha, com Hitler, em 1933), Benjamin experimentaria sua existência como diáspora. Como se sentisse na própria pele a condição sempre precária do Povo Eleito, do qual ele mesmo fazia parte e que, em determinado momento de sua vida, Ihe abrirá um horizonte algo místico, o que se intensificará com sua aproximação a Gersom G. Scholem. É o que se pode notar, por exemplo, com um olhar mais atento, em suas teses Sobre o Conceito da História, de 1940 - em que o tema da redenção é mencionado num horizonte teo-filosófico.

Influenciado - entre tantos outros - por poetas como Charles Baudelaire, Paul Valéry e Bertolt Brecht, e por filósofos como György Lukács e Theodor W. Adorno1 - com quem mantivera uma extensa correspondência, além de próceres ligados ao universo das artes dramáticas, tal como Asja Lacis. Todas essas decisivas figuras vinculadas às mais variadas correntes de pensamento o teriam incitado a um despertar para inquietações sobre estética, temporalidade, história, modernidade e também para as questões trazidas à tona pelo marxismo. Foi assim que o filho de um comerciante judeu de objetos de arte escreveu um dos capítulos mais belos e tristes da história do pensamento ocidental.

1 Será pela influência e insistência de Adorno que Benjamin fará parte do grupo de pensadores do Instituto de Pesquisa Social, a futuramente conhecida Escola de Frankfürt. Para um maior entendimento sobre o tema confira WIGGERSHAUS (2002). 
Entrementes, o objetivo do presente artigo é explicitar um dos conceitos fundamentais de sua produção estética: a aura - sobretudo, no que tange à Fotografia e ao Cinema. Assim, mediante uma arqueologia do conceito, pretendemos esboçar também como alguns de seus comentadores interpretaram as possíveis relações entre a estética benjaminiana e as transformações sociais da Modernidade.

\section{A aura na estética de Walter Benjamin I: origem e primeiras abordagens}

A primeira vez que Benjamin mencionou o conceito aura foi num ensaio de 1931, intitulado Pequena História da Fotografia. O texto, conciso, após falar das diferenças entre um quadro pintado por um artista e o resultado da técnica que a fotografia ensejara, faz ponderações importantes à nossa explanação. Assim, para ele a noção de aura parece ser visada, num primeiro momento, como resultado de certo primitivismo da técnica fotográfica: quando as placas de prata iodadas (os clichês de Daguerre) eram chamuscadas pela luz dentro da câmara obscura o objeto fotografado era envolvido por um halo que o circundava, dando a impressão de que uma aura misteriosa era revelada.

$\mathrm{Na}$ fotografia surge algo de estranho e de novo [...]: a técnica mais exata pode dar às suas criações um valor mágico que um quadro nunca mais terá para nós [...]. A natureza que fala à câmera não é a mesma que fala ao olhar; é outra [...] Só a fotografia revela esse inconsciente ótico, como só a psicanálise revela o inconsciente pulsional. (BENJAMIN, 1987a, p. 93-94).

Importante é realçar, nesta primeira abordagem, que o tempo e o espaço são determinantes para que a escrita da luz aconteça. Então, é necessário respeitar as condições do ambiente para que a foto revele algo, de fato.

A fraca sensibilidade luminosa das primeiras chapas exigia uma longa exposição ao ar livre. Isso por sua vez obrigava o fotógrafo a colocar o modelo num lugar tão retirado quanto possível, onde nada pudesse perturbar a concentração necessária ao trabalho [...] 0 próprio procedimento técnico levava o modelo a viver não ao sabor 
do instante, mas dentro dele; durante a longa duração da pose ele por assim dizer crescia dentro da imagem. (BENJAMIN, 1987a, p. 96).

Contudo, para Benjamin, a aura não é, apesar das condições-limite da técnica, apenas um registro mecânico. É, também, a experiência do olhar que busca capturar o hic et nunc da manifestação aurática como epifania do ser. No transcorrer do mesmo texto ele nos oferece uma definição:

Em suma, o que é a aura? É uma figura singular, composta de elementos espaciais e temporais: a aparição de uma coisa distante, por mais próxima que ela esteja [...] Mas, fazer as coisas se aproximarem de nós, ou antes das massas, é uma tendência tão apaixonada do homem contemporâneo quanto a superação do caráter único das coisas, em cada situação, através de sua reprodução. Cada dia fica mais irresistível a necessidade de possuir o objeto de tão perto quanto possível, na imagem, ou melhor na sua reprodução. E cada dia fica mais nítida a diferença entre a reprodução, como ela nos é oferecida pelos jornais ilustrados e pelas atualidades cinematográficas, e a imagem. Nesta, a unicidade e a durabilidade se associam tão intimamente como, na reprodução, a transitoriedade e a reprodutibilidade. (BENJAMIN, 1987a, p. 101).

Ora, na concepção benjaminiana a fotografia alterara, dessa forma, a própria natureza do que podemos chamar arte. E, mais do que isso, ocasionara, ainda, uma mudança substancial em nossa percepção. As transformações técnicas possibilitadas pela Modernidade reestruturaram, por assim dizer, as condições do observador ao transtornarem o espaço vital onde este se enraizava como homem do seu tempo. Há, pois, uma redefinição do pensamento sobre a reprodução que escapa à mera concepção de cópia que encontramos na mais antiga tradição filosófica. Exemplo disso é "[...] a concepção de Platão que define a arte como mimesis², a arte sendo, neste contexto ontológico, imitação de algo cuja

2 Mímesis, do grego, Imitação, está intimamente relacionada com Methéxis: Participação. Neste tipo de abordagem, a Imitação é, de certa forma, "assegurada" por sua participação no mundo das ideias. Os simulacros, por assim dizer, ao qual temos acesso pela realidade tangível - que afeta e obnubila nossos sentidos -, são, portanto, cópias imperfeitas de referentes universais, belos, verdadeiros e, eminentemente reais. 
própria essência é invisível" (BOISSIERE, 2003, p. 2-3). Doravante, o pensador berlinense, historicamente já bem distante do ateniense Platão,

[...] desenvolve uma reflexão cujos termos são inteiramente novos com relação à tradição filosófica [...] eles deslocam, de cara, as categorias às quais nós estamos acostumados em matéria de estética [...] Ele tenta pensar as consequências humanas e sociais das alterações perceptivas ligadas ao desenvolvimento da técnica. Isto para elaborar uma estética, isto é, uma teoria da percepção que seja histórica e dialética. (BOISSIERE, 2003, p. 2-3).

Ademais, em outro ensaio denominado A Obra de Arte na Era de sua Reprodutibilidade Técnica, de 1935/6 o vocábulo aura será novamente colocado em xeque. Aliás, em uma carta dirigida a Max Horkheimer, datada de 16 de outubro de 1935, Benjamin mencionara pela primeira vez o estudo sobre a Obra de Arte, classificando-o, simplesmente, de considerações provisórias. Temos, entretanto, aqui, um texto polêmico, que conheceu (pelo menos) quatro versões, remanejadas entre 1935 e 1939 - e nem sempre pelo próprio autor.

No entanto, neste ensaio benjaminiano, de acordo com denúncia da revista Alternative, muitas alterações foram realizadas, como nota o professor Flávio René Kothe (KOTHE, 1978, p-34-35). Aparecem, aí, várias distorções: em lugar de comunismo, é utilizado as forças construtivas da humanidade; em lugar de fascismo aparece doutrinas totalitárias; em vez de a guerra imperialista é utilizado a guerra moderna; no lugar de as massas têm o direito de transformar as relações de propriedade aparece a frase atenuada as massas tendem à transformação das condições de propriedade; em vez de na União Soviética o próprio trabalho toma a palavra utilizara-se o próprio trabalho fala por si só, entre outras. Doravante, tais mudanças:

[...] restringem a terminologia marxista e diminuem o radicalismo de suas formulações. São um sintoma das restrições que Benjamin sofreu neste e noutros trabalhos seus, tanto assim que preparou uma terceira versão para Brecht. As cartas de Benjamin que discutiam as modificações feitas [...] foram excluídas da edição de 
sua correspondência organizada por Adorno e Scholem. (BOISSIERE, 2003, p. 35).

Resumidamente, no ensaio ora em foco,

Benjamin afirma que, com a reprodução técnica, o aqui e o agora característicos da obra de arte desparecem ou, no mínimo, se desvalorizam, destruindo-se assim o que ele denominou 'aura'. O aqui e o agora (hic et nunc), além de implicarem na duração material da obra e na sua capacidade de testemunho histórico, constituem a sua legitimidade $[\ldots]$ e originalidade. A reprodutibilidade técnica acarreta outro tipo de percepção, por um lado atrofiadora da diferença e, por outro, dessacralizadora. Por sua vez, a própria necessidade de obras reproduzidas tecnicamente, possibilitadas pelo desenvolvimento tecnológico, decorre de mudanças no processo de produção (caracterizadas especialmente pela mecanização), que diminuem a capacidade de percepção do diferenciado a ponto de atingirem [...] o caráter único da obra de arte. (BOISSIERE, 2003, p. 36).

O fato é que, para Benjamin, a obra de arte foi, desde os seus primórdios, reprodutível. O desenvolvimento de novas técnicas viera aumentar em larga escala e, de certa forma, qualitativamente, as possibilidades de expansão da aura. E isto não só pelo objeto em si reprodutível, mas pela alteração da perceptibilidade do sujeito que o observa.

Importante é lembrar que a Modernidade trouxera consigo uma poderosa revolução tecnológica. Com os desdobramentos das constantes Revoluções Industriais pelas quais passaram os séculos XVIII, XIX e XX levando também em conta as transmutações paradigmáticas no campo das Ciências Naturais -, a velocidade da produção em série e a massificação das coisas como fenômeno que a tudo toca, que a tudo desencanta. Nesse contexto, a arte perdera seu valor de culto adquirindo um valor de mercado. Ademais, não há tempo para a contemplação: tudo - ou quase - é fugidio diante da tentativa de captura pela percepção humana. Com isso, paradoxalmente, ocorrera uma ampliação de nossas próprias capacidades perceptivas. Exemplo disso é o cinema. 


\begin{abstract}
Alargando o mundo dos objetos dos quais tomamos conhecimento, tanto no sentido visual como no auditivo, o cinema acarretou, em consequência, um aprofundamento da percepção. $E$ é em decorrência disso que as suas realizações podem ser analisadas de forma bem mais exata e com número bem maior de perspectivas do que aquelas oferecidas pelo teatro ou a pintura [...] E é daí que provém a sua importância capital - tende a favorecer a mútua compenetração da arte e da ciência (BENJAMIN, 2017, p. 37-38).
\end{abstract}

Como desdobramento minimamente favorável a este desencantamento, a obra, assimilada pela reprodutibilidade, assume, entretanto, um caráter mais democrático - apesar da ambiguidade que circunda tal definição. Neste ponto, Benjamin acredita que a técnica pode transformar-se em ferramenta para viabilizar caminhos mais prósperos para a humanidade.

O cinema, por exemplo, possui o poder de nos restituir um senso de identidade e coletividade, aproximando a realidade ao homem e promovendo uma relação harmoniosa entre este e a natureza, ainda que tal forma de reprodução se Ihe afigure mais invasiva na percepção humana da realidade do que a própria fotografia ${ }^{3}$.

Com esta aproximação da realidade mediante as técnicas de reprodução, perde-se a distância natural da aura. A suposta dimensão positiva da técnica apontada por Benjamin remete ao fato de que, diante do caos, a humanidade pode se locomover em direção a um novo tempo, uma nova cultura próxima da promessa de felicidade, sem os erros de outrora e os aspectos negativos da tradição.

3 Para entender essa invasividade com maior profundidade, "é preciso voltar à técnica de produção da imagem fílmica, tal como Walter Benjamin a apresenta na seção intitulada 'Pintor e cinegrafista', na qual irá confrontar a técnica do operador à do pintor. O primeiro comporta-se perante a realidade como o cirurgião diante do paciente. Inversamente, o modo de ação do pintor é associado ao curandeiro (Magier). Este 'conserva a distância natural existente entre ele e o paciente', bem como aquele que pinta, na sua prática, 'observa uma distância natural entre a realidade dada e ele próprio'. Ao contrário, o cinegrafista 'penetra', assim como o cirurgião durante a operação, 'na própria natureza do dado'". (PALHARES, 2006, p. 64). 
O declínio da aura, associado ao potencial da reprodutibilidade técnica, abre uma (ou mais) discussão sobre novas possibilidades de um percipere da mesma a partir de uma dimensão algo libertadora (da aproximação das massas por meio da técnica).

É importante salientar que esta suposta tendência progressista é apontada por ele como um meio de acabar (ou atenuar) a apropriação da técnica pelo totalitarismo a serviço, portanto, de um ideal de dominação (a arte-propaganda nazista, por exemplo) - o que inverte, não obstante, uma posição que se Ihe afigurava quase onipresente na Europa. Pois, se acontece "a estetização da política praticada pelo fascismo, o comunismo respondeIhe com a politização da arte". (BENJAMIN, 2017, p. 47).

\section{A aura na estética de Walter Benjamin II: releituras de um conceito}

Interessa-nos ainda considerar a problemática sob um ângulo complementar. Em outro texto, intitulado Sobre Alguns Temas em Baudelaire, Benjamin afirma que a experiência aurática na obra de arte é uma experiência em que a aura aparece (manifesta-se) em um instante de retribuição do olhar do sujeito observador. No ato de contemplação da aura, há uma espécie de troca de olhares, de reconhecimento de semelhanças e correspondências entre o sujeito e a obra contemplada: "perceber a aura de uma coisa significa investi-la do poder de revidar o olhar". (BENJAMIN, 1989 , p. 140.).

Contrária à experiência particular (Erlebnis), entendida como vivência individual e fragmentada dos indivíduos inseridos na dinâmica das cidades, a experiência transformadora (Erfahrung), algo transcendental, se Ihe afigura uma relação única, reconciliatória e reflexiva com o Mundo, que remete ao resgate da coletividade e da tradição associada a uma cultura renovada, compartilhada. 
Num colóquio realizado no Instituto de Teoria da Literatura e Literatura Comparada da Universidade de Berlim, em 1968, Gersom G. Scholem - perguntado sobre o significado da aura em Benjamin defendera, desta, o sentido eminentemente místico-teológico: ela, a aura, designaria a luz invisível que rodeia uma aparição, o prolongamento psícofísico de uma pessoa: tudo o que vive e respira manifesta a luminosidade emanada da Presença do Eterno que abraça sua criação, sobretudo o homem e a mulher: imagem do Deus de Israel (Gn. 1, 26-27), nos quais se vê (retribuição do olhar) o próprio Criador - pois o rosto é a morada da aura, ou seja, ela "acena pela última vez na expressão fugaz de um rosto [...]. (BENJAMIN, 1987a, p. 174). Transparece ainda, sobretudo no ensaio sobre A Obra de Arte na Era de sua Reprodutibilidade Técnica, outro sentido, o secularizado.

\begin{abstract}
Benjamin acompanhando Baudelaire, provocou uma secularização desse termo proveniente da esfera religiosa - e a escolha dele não é ocasional: aponta para a origem mágico-religiosa da arte, cujas obras eram representações de entidades pretensamente transcendentais [...] Daí também o elogio benjaminiano da reprodução técnica, enquanto processo de destruição da sacralidade aurática. Noutros termos, a reprodução técnica se insere num processo de racionalização, de destruição do mito e dessacralização do mundo. (KOTHE, 1978, p. 41).
\end{abstract}

Vale, aqui, a transcrição de um poema em prosa do próprio Baudelaire, intitulado A Perda da Auréola e datado de 1864/5:

- O quê? Você por aqui, meu caro? Num lugar suspeito? Você, o bebedor de quintessências? O comedor de ambrosia? Na verdade, devo surpreender-me! - Você conhece, caro amigo, meu pavor pelos cavalos e pelos carros. Ainda há pouco, quando atravessava a avenida, apressadíssimo, e saltitava na lama em meio a esse caos movediço em que a morte chega a galope por todos os lados ao mesmo tempo, minha auréola, num movimento brusco, escorregou da minha cabeça para a lama da calçada. Não tive coragem de juntá-la. Julguei menos desagradável perder minhas insígnias do que deixar que me rompessem os ossos. E depois, pensei, há males que vêm para bem. Posso agora passear incógnito, praticar ações vis e me entregar à devassidão, como os simples mortais. E aqui estou, igualzinho a você!

- Você deveria ao menos mandar pôr um anúncio pela auréola, ou mandar reavê-la pelo delegado. - Não, ora essa! Sinto-me bem 
aqui. Só você me reconheceu. A dignidade, aliás, me entedia. E também, me alegra pensar que algum poeta ruim há de juntá-la e vesti-la imprudentemente. Fazer alguém feliz, que prazer! Principalmente um feliz que ainda vai me fazer rir! Pense em $X$ ou em Z, puxa! Que engraçado vai ser! (BAUDELAIRE, 2011, p. 214).

Interessante é notar seu desprezo por aquilo que o tornava diferente. É O advento dessacralizador da Modernidade: Diz ele julgar menos desagradável perder o que o referenciava como sacro, celeste, imortal do que morrer: "e depois, pensei, há males que vêm para bem. Posso agora passear incógnito, praticar ações vis e me entregar à devassidão, como os simples mortais" (BAUDELAIRE, 2011, p. 214). Agora, sim, desencantado, massificado, ele se tornara igualzinho a todos nós, consumidores, filhos e filhas de um Novo Tempo ${ }^{4}$.

A pesquisa do escritor e crítico de arte francês, Jean-Louis Poitevin, reafirmou a origem teológica da aura. Ela designa - como apontado por Scholem - o círculo dourado que envolve as cabeças da Virgem Maria, do Cristo e dos santos nos ícones. Na obra de Benjamin, doravante, o termo apresenta uma significação ao mesmo tempo precisa e indeterminada5. E, antes de ser utilizado no campo da estética, este era mencionado em experiências de caráter pseudo-transcendentais ou místicas como resultado da ampliação da percepção humana favorecida, de algum modo, pelo uso

\footnotetext{
4 "Frequentemente essa pequena narrativa é interpretada como uma própria imagem da teoria benjaminiana da perda da aura. Benjamin induz a isso quando termina seu texto sugerindo uma associação entre a perda da auréola do lírico que atravessa o bulevar e a da aura: 'Ele [Baudelaire] determinou o preço que é preciso pagar para adquirir a sensação do moderno: a destruição [Zertrümmerung] da aura na vivência do choque'. Vivência do choque que em Baudelaire não pode ser dissociada de suas andanças em meio à massa." (PALHARES, 2006, p. 83).

5 Como bem apontado, mais recentemente, por Rolf-Peter Janz, "quem perguntar pela modernidade daquilo que Benjamin denomina de 'aura' e 'experiência aurática' deveria partir do pressuposto de que esse termo não designa - e, provavelmente, nem poderia designar - uma concepção unívoca em seus escritos. Pelo contrário: Benjamin reformulou seu conceito várias vezes, enriquecendo-o com mais exemplos e novas descobertas" (GINZBURG, J; SELDMAN, S., 2012, p.13).
} 
de psicotrópicos por poetas do século XIX, como o próprio Baudelaire e o haxixe, por exemplo6.

Assim, tais experiências nos permitiriam ver coisas que não nos são visíveis nas condições normais de nosso aparelho ótico, humano. Algo que a fotografia, por sua vez, possibilitara, ao revelar novas e inauditas facetas da realidade por meio das potencialidades tecnológicas intrínsecas a instrumentos cada vez mais avançados.

Destacamos, por fim, a tendência dialética do que Benjamin nomeou aura. Se o fenômeno ao qual nos referimos até aqui emerge não só de uma propriedade intrínseca a um objeto, mas é também dependente da percepção de quem sabe ver, então a aura não é coisa que se perde. É como um lastro de origem mistérica como a própria vida, estando sempre presente na entranhada relação de mútua abertura e acolhida entre a arte e seu produtor, ou entre aquele que dela se apropria por um olhar livre dos vícios visuais, autônomo em sua busca irreflexa pelo que brilha e que sacraliza a tudo aquilo que nos toca no mais íntimo de nós mesmos, em um processo contínuo de atualização de sentido. Esteja latente ou se patenteie na fugacidade de um tempo cada vez mais veloz, a aura pode se transformar, contudo não se transubstancia continuando um fenômeno recidivo que faz da arte o que ela é: uma experiência única de caráter redentor, soteriológico, salvífico. Uma porta aberta para um sentido de definitividade que faz da existência humana uma antecipação da eternidade.

\footnotetext{
${ }^{6}$ De acordo com Leandro Konder, o próprio Benjamin "se interessou pela embriaguez; e, na esteira desse interesse, ficou atraído pelo haxixe [...] Entrou em contato com os médicos e, sob orientação deles (e em companhia de Ernst Bloch), experimentou o haxixe, em 1928" (KONDER, 1999, p. 52).
} 


\section{Considerações finais}

Muito se tem escrito nos últimos anos sobre Walter B. S. Benjamin no que concerne, especialmente, às suas concepções acerca da natureza da arte, revolucionada com as formas de reprodução tecnológicas dos séculos XIX e XX. Sua produção no campo da estética, onde posicionamos nossa leitura sobre o conceito de aura, trouxera à tona questões sóciopolíticas (e que, aqui, foram tangenciadas apenas de modo periférico). Isso o mantivera como um pensador capaz de construir uma visão abrangente e algo profunda sobre a complexa realidade de seu tempo. As influências que recebera, evidentemente, não passaram ao largo dessa produção.

Não é sem razão que sua relevância, cremos, provém do fato de que ele, no campo comunicacional - sobretudo, do cinema - propôs uma leitura que enfeixava em um olhar multidisciplinar a clareza da reflexão marxiengeliana, os ganhos da psicanálise freudiana e a acuidade e sensibilidade poética de Baudelaire, sobretudo. Importante é lembrar - diante do que acabamos de expor -, que Benjamin já entrevia, na primeira metade do século $\mathrm{XX}$, o poder transformador do cinema como mídia de massa. Isso naquilo que ele poderia trazer de nefasto (com sua manipulação pela máquina de guerra nazista) e naquilo que ele poderia, por outro lado, trazer de civilizatório (sua utilização para a conscientização das próprias massas). Por fim, é assim que para nós Benjamin permanece: uma trilha do saber aberta para quem quiser - e puder - por ela caminhar, numa flanêrie despreocupada, contudo, atenta às múltiplas belezas dessas paisagens que ele oferece a quem dele se aproxima. 


\section{Referências}

BAUDELAIRE, Charles. Pequenos poemas em prosa. São Paulo: Hedra, 2011. BENJAMIN, Walter. A obra de arte na era de sua reprodutibilidade técnica. 3. ed. São Paulo: Brasiliense, 1987a.

BENJAMIN, Walter. Charles Baudelaire: um lírico no auge do capitalismo. São Paulo: Brasiliense, 1989.

BENJAMIN, Walter. Estética e sociologia da arte. Belo Horizonte: Autêntica Editora, 2017.

BOISSIERE, Anne. La reproductibilité technique Chez Walter Benjamin. Revue DEMéter, Décembre, 2003. Université de Lille - 3. Disponível em:< http://demeter.revue.univ-lille3.fr/copie/boissiere.pdf>. Acesso em: 17 fev. 2018.

GINZBURG, Jaime; SELDMAN, Sabrina (Orgs.). Walter Benjamin: rastros, aura e história. Belo Horizonte: Editora da UFMG, 2012.

PALHARES, Taísa Helena Pascale. Aura: a crise da arte em Walter Benjamin. São Paulo: Barracuda, 2006.

KONDER, Leandro. Walter Benjamin: o marxismo da melancolia. 3. ed. Rio de Janeiro: Civilização Brasileira, 1999.

KOTHE, Flávio René. Benjamin e Adorno: confrontos. São Paulo: Ática, 1978.

WIGGERSHAUS, Rolf. A escola de Frankfurt: história, desenvolvimento teórico, significação política. Rio de Janeiro: Difel, 2002. 